\title{
Autoimmune Reactivity in Graft Injury: Player or Bystander?
}

\author{
Vrushali V. Agashe ${ }^{1,2,4}$ • William J. Burlingham ${ }^{1,3}$
}

Published online: 7 July 2015

(C) Springer International Publishing AG 2015

\begin{abstract}
Organ transplantation is the only viable treatment for several end-stage organ failures. However, chronic rejection prevents long-term graft survival. Traditionally, this rejection was attributed to the development of alloimmunity in transplant patients. However, recent evidence suggests that autoimmunity plays a larger role in chronic rejection of certain organ transplants, than alloimmunity. In this review, we will focus on the history of autoimmunity in solid organ transplantation and look at the collagen type $\mathrm{V}, \mathrm{K} \alpha 1$ tubulin, vimentin, cardiac myosin, and heat shock proteins as classical examples of autoantigens in organ transplantation. We will also look at some of the recent reports looking at the mechanisms of autoimmunity and try to provide answers to some of the age-old questions in autoimmunity.
\end{abstract}

Keywords Autoimmunity · Collagen type $\mathrm{V} \cdot \mathrm{K} \alpha 1$ tubulin . Vimentin $\cdot$ Cardiac myosin $\cdot$ Heat shock protein 65

This article is part of the Topical Collection on Immunology

William J. Burlingham

burlingham@surgery.wisc.edu

Vrushali V. Agashe

agashe@surgery.wisc.edu

1 Department of Surgery-Transplant Division, School of Medicine and Public Health, University of Wisconsin Madison, Madison, WI 53795, USA

2 Clinical Science Center, University of Wisconsin Madison, H4/747, Madison, WI 53792, USA

3 Clinical Science Center, University of Wisconsin Madison, G4/702, Madison, WI 53792, USA

4 Comparative Biomedical Sciences Graduate Program, University of Wisconsin Madison, Madison, WI, USA

\section{Introduction}

Solid organ transplantation remains the only viable option for end-stage organ pathology. Advancement in surgical procedures, administration of immunosuppressants, and careful patient monitoring have all greatly controlled acute rejection episodes. However, the long-term survival of solid organs is hampered by the development of chronic rejection.

Lung transplantation is a therapy for several chronic lung diseases such as chronic obstructive pulmonary diseases (COPD), idiopathic pulmonary fibrosis (IPF), and cystic fibrosis $(\mathrm{CF})$. In lung transplantation, chronic rejection manifests as obliterative bronchiolitis (OB). Since the diagnosis of $\mathrm{OB}$ is difficult without histology, it is clinically defined as bronchiolitis obliterans syndrome (BOS). BOS is diagnosed as a sustained drop in forced expiratory volume in $1 \mathrm{~s}\left(\mathrm{FEV}_{1}\right)$ to $66-80 \%$ (BOS1), $65-51 \%$ (BOS2), or below $50 \%$ (BOS3) [1]. Even with the advances in surgical sciences, bronchiolitis obliterans remains a major obstacle to long-term lung transplant survival in patients. The 5-year survival rate for lung transplant is low at about $50 \%$, with BOS, graft failure, and infections being the major causes of death [2].

For all (adult and pediatric) cardiac transplants, the 5-year survival rate is at $69 \%$ much higher than lung transplants. But, similar to lung transplants, graft failure due to acute and chronic rejection remains the biggest cause of heart rejection following cardiac transplantation [3].

Autoimmunity is defined as an immune response against any self-antigen. It may be cell- or antibody-mediated. Several autoimmune diseases and their target autoantigens have been documented such as Goodpasture's disease (Collagen Type IV), myasthenia gravis (acetylcholine receptor), multiple sclerosis (MOG, PLP, and MBP), type 1 diabetes (GAD and insulin) and rheumatoid arthritis (Collagen Type II and Fc). Historically, organ rejection has been attributed to the 
development of alloimmunity, i.e., T cells targeted against the donor HLA, along with B cells producing donor-specific antiHLA antibodies, ultimately leading to graft loss. However, recent evidence supports the notion that autoimmunity does indeed play an active role in chronic rejection.

In this review, we will discuss the role that autoantigens play in the development and progression of chronic rejection in solid organ transplants. We will also explore some of the hypotheses behind the development of autoimmunity and raise some interesting questions on the role of autoimmunity in transplantation and immunology as a whole.

\section{Autoantigens in Transplantation}

Some of the well-studied autoantigens in transplantation include collagen type $\mathrm{V}(\mathrm{ColV}), \mathrm{K} \alpha 1$ tubulin, vimentin, cardiac myosin, and heat shock proteins (Hsps) among others. One important consideration in transplant autoimmunity is the fact that some of these proteins under normal circumstances remain sequestered from the immune system. It can be hypothesized that under normal circumstances, some of these proteins are exposed only after a trauma but are subsequently controlled by the immune system and sequestered to prevent long-term exposure. Thus, these can be termed as sentinel antigens left sequestered after activation (SALSAAs).

ColV [4] and K $\alpha 1$ tubulin [5] (also known as tubulinA1B) are the two most important autoantigens implicated in lung transplantation. ColV is a minor fibrillar collagen embedded within the major collagen type I (ColI), the mature collagen fibril. It is thus sequestered from the immune system during normal growth and development $[6,7]$. ColV is present as a heterotrimer consisting of one $\alpha 2$ chain and two $\alpha 1$ chains in the peribronchial and the perivascular regions in the lung tissue [8-10]. The N-terminal non-collagenous region of the ColV $\alpha 1$ chain containing the variable and PARP domains protrudes from the mature fibrils in tissues, but the collagenous region remains buried within the fibrils. Yet, most of the immune response against ColV is directed toward its sequestered collagenous region. Within the lung tissue, ColV is normally not accessible to antibodies used for immunostaining; however, its presence can be revealed by partial digestion $[6$, 11] or by ischemia/reperfusion injury, as in a lung isograft [12]. ColV can also be found on the surface of bronchial epithelial cells under certain conditions [13]. Similar to ColV, $\mathrm{K} \alpha 1$ tubulin is a sequestered antigen remaining within the cell or within the gap junction. It is also known to interact with other proteins present in the gap junctions [14]. It is $\sim 50 \mathrm{kDa}$ and is found both within and on the surface of lung epithelial cells.

The three well-studied autoantigens in cardiac and kidney transplants are cardiac myosin, vimentin, and Hsps. Cardiac myosin is the major contractile protein essential for the proper functioning of the heart [15]. Vimentin is a member of the intermediate filament family that is important in maintaining several cytosolic organelles and also important in other functions of both eukaryotic and prokaryotic cells [16]. Vimentin usually remains sequestered within the cell; however, it can be secreted into the matrix under inflammatory conditions [17]. Hsps were identified several years ago as chaperone proteins important in proper folding and expression of proteins. Recently, a new role for Hsps in the immune system has emerged [18] including their role in transplantation.

In this review, we will focus on the history of these five autoantigens - ColV, K $\alpha 1$ tubulin, vimentin, cardiac myosin, and Hsp65 in transplantation. We will also discuss some of the recent developments in this field and provide an interesting approach to look at autoimmunity.

\section{Collagen Type V in Lung Transplantation}

The earliest evidence for the involvement of ColV reactivity in lung transplants patients came during the 1990s. David Wilkes' lab demonstrated an increased $\operatorname{IgG} 2 / \operatorname{IgG} 1$ ratio in the brochoalveolar lavage (BAL) of lung allograft recipients undergoing acute rejection along with up-regulated $T_{h} 1$ cell activity [19]. This was further recapitulated in a murine lung graft versus host $(\mathrm{GVH})$ model, by instilling allogeneic BAL samples into the lungs of recipient mice. Interestingly, IgG2a deposition was seen in the perivascular and peribronchiolar tissues [20].

During the early stages of understanding ColV reactivity in lung transplantation, it was discovered that ColV could actually be used to down-regulate acute rejection episodes. In order to demonstrate this, the authors used the same model of introducing allogeneic BAL cells into the lungs of mice, which results in an acute GVH reaction, with local production of tumor necrosis factor $\alpha$ (TNF $\alpha)$. However, if ColV was instilled into the lungs before the introduction of allogeneic cells, GVH as well as the levels of TNF $\alpha$ were down-regulated, hinting toward a role of ColV in lung transplantation [21].

In order to substantiate these results, a rat lung allograft model was used. WKY rats (RT1) were orally fed ColV before receiving an F344 $\left(\mathrm{RT}^{\mathrm{lv} 1}\right)$ lung allograft. Animals that received control (Col II) pre-treatment developed severe acute rejection and pulmonary fibrosis. Rats that were orally treated with ColV showed decreased acute rejection pathology as well as significantly delayed development of chronic OB lesions within the allograft. The authors attributed this to a global increase in transforming growth factor $\beta(\operatorname{TGF} \beta)$ levels seen in mice tolerized with ColV [22, 23].

It was in 2002 that the first concrete evidence for the role of ColV reactivity in lung allograft rejection was published [24]. ColV peptides were detected in the BAL fluid of rats receiving either an allograft or an isograft but not in BAL of normal 
lungs. Two ColV-reactive T cell lines, namely, LT1 and LT3, were obtained from allografts and adoptively transferred into animals receiving isografts. Surprisingly, LT1 induced pathology in the isograft and also broke tolerance to an allograft that was induced orally by ColV treatment as previously described. This led to the idea that maybe alloimmunity was not needed for the induction of lung immune damage but that ColV reactivity alone could determine tolerance or rejection in lung transplants [24].

Yoshida et al. further studied the idea that autoimmunity was a player in chronic rejection and was independent of alloimmunity [12]. Immunohistochemistry staining revealed that while the native right lung showed no/low expression of ColV, ColV could easily be detected in healed left lung isografts several days after transplantation; there was more localized but still substantial expression of ColV detectable around bronchioles on day 30. The authors then transferred ColV or hen egg lysozyme (HEL)-specific lymphocytes into rats receiving an isograft, either at day 5 or at day 30 after transplantation. Only the animals receiving ColV-reactive lymphocytes, but not HEL reactive lymphocytes, showed signs of rejection-like pathology, irrespective of whether the cells were introduced on day 0 or day 30 after transplantation, while the native lung remained completely unaffected. This report was also one of the early reports hinting at a role of interleukin 17 (IL17) in ColV reactivity, as IL17 messenger RNA (mRNA) transcripts could be detected in fresh isografts as well as in the lymph node cells obtained from rats that were immunized with ColV [12].

The authors thus demonstrated that ischemia-reperfusion injury (IRI) by itself was sufficient to induce sensitivity and subsequent damage due to ColV reactivity without the presence of alloimmunity. They hypothesized that the IRI, caused as a result of surgery, leads to the release of ColV or ColV antigenic fragments into the local environment of the graft. Over time, these persist and give rise to ColV reactivity [12], either in the context of reactivity to alloantigens also present on the transplant that could lead to chronic rejection or in the context of a pre-existing immunity to ColV, which could result in acute rejection pathology indistinguishable from alloimmune rejection.

In 2007, the first definitive report implicating $\mathrm{CD}^{+} \mathrm{T}_{\mathrm{h}} 17$ cells in the development of ColV autoreactivity in lung transplant patients was published [4]. In contrast to the response to the recall antigen, tetanus toxoid (TT), which was dependent on $\mathrm{CD}^{+} \mathrm{T}_{\mathrm{h}} 1$ cells making interferon $\gamma(\mathrm{IFN} \gamma)$, the ColV response was IFN $\gamma$ independent but highly dependent on IL17, IL1 $\beta$, and TNF $\alpha[4,25]$. Some other reports have also demonstrated an IFN $\gamma$ response against self-antigens, including ColV; however, the role of IFN $\gamma$, if any, remains controversial [26]. More importantly, the presence of ColV autoreactivity was strongly associated (H.R. $=9.8, p<0.04$ ) with the development of severe BOS (grades 2-3), suggesting that ColV autoimmunity plays a role in chronic rejection in lung transplant recipients [4]. This report supported the previously described phenomenon that in vivo neutralization of IL1 $\beta$ or TNF $\alpha$ decreased the obliterative disease in tracheal allografts in mice [27]. The role of ColV in lung allograft rejection was also supported using a rat lung transplant model. Co-transfer of ColV-specific $\mathrm{T}_{\text {effector }}\left(\mathrm{T}_{\text {eff }}\right)$ cells and $\mathrm{T}_{\text {regulatory }}$ $\left(T_{\text {reg }}\right)$ cells actually reduced the rejection seen in rat isograft lung transplants $[12,25]$, while the transfer of ColV-specific but not HEL-specific lymph node cells into WKY rat lung isograft recipients reproduced the histopathology of obliterative bronchiolitis in the absence of alloimmunity [4].

Antibodies to ColV have also been detected in the serum of lung transplant patients. Pre-transplant antibodies to ColV were significantly correlated with development of primary graft dysfunction (PGD) immediately post-transplant and subsequently with BOS [28-30]. Antibodies to the $\alpha 1$ chain of the ColV molecule have also been detected in the BAL fluid from lung transplant patients, as well as in the murine orthotropic lung transplant model [31]. Lungs from a minor $\mathrm{H}$ antigenmismatched $\mathrm{C} 57 \mathrm{BL} / 10\left(\mathrm{H}-2^{\mathrm{b}}\right)$ mouse are transplanted into a C57BL/6 $\left(\mathrm{H}-2^{\mathrm{b}}\right)$ mouse. By day $21 \mathrm{OB}$ develops in $50 \%$ of the grafts with the development of IL17-based $\mathrm{CD}^{+} \mathrm{T}_{\mathrm{h}}$ responses against ColV [32]. Moreover, ColV is overexpressed in and around the fibrotic lesions in patient samples as well as in the murine OB model [13]. Increase in IL17 levels in airway epithelial cells (AECs) induces an overexpression of the $\alpha 1$ chain of the ColV molecule as well as down-regulates complement regulatory proteins (CRPs), all of which ultimately lead to the development of $\mathrm{OB}$ and chronic rejection $[13,33]$. Interestingly, there is a feedback loop between complement component C3a and IL17. Increased C3a due to decreased CRPs increases IL17 production in response to ColV [33].

Recently, the ColV reactivity in lung transplant patients was found to have a DR bias. In a cohort of pre-lungtransplant patients, who were ColV reactive, $53 \%$ were found to have HLA-DR1501 (DR15) haplotype. But, post-lung transplant, HLA-DR0101 (DR1) and HLA-DR0301 (DR17) but not DR15 were enriched within the ColV-reactive population. However, post-lung transplant, patients receiving a DR15 donor were found to be at a higher risk for BOS development [34•]. The mechanistic basis for this unusual finding will be discussed below.

Additionally, it has been shown that the $\mathrm{T}$ and $\mathrm{B}$ cell responses against ColV were actually directed against the $\alpha 1$ chain of the molecule $[35,36,37 \bullet \bullet]$. Subsequently, peptides/potential epitopes of the ColV $\alpha 1$ chain were identified (Table 1). It is interesting to note that only two peptides were found to bind HLA-DQ alleles, but the same two peptides bound the strongest to the mouse class II, I-A (b) [34•].

More recently, $T_{h} 17$ responses have been found to be dependent on an ATP-gated ion channel, namely, the P2X7 receptor (P2X7R). Both the ColV and the ColV peptide 
Table 1 ProImmune REVEAL binding assay-identified peptides of ColV $\alpha 1$ chain that bound to DR1 and DR15

Collagen type $\mathrm{V} \alpha 1$ peptides

\begin{tabular}{lll}
\hline ColV $\alpha 1$ peptide & Sequence & Specificity \\
\hline p629 & DRGFDGLAGLPGEKG & DR1 \\
p779 & PPGPQGPIGYPGPRG & DR15 \\
p789 & PGPRGVKGADGIRGL & DR15 \\
p799 & GIRGLKGTKGEKGED & DR1, DR15 \\
p1049 & KDGPPGLRGFPGDRG & DR15 \\
p1439 & LRGIPGPVGEQGLPG & DR1, DR15 \\
p599 & PPGPAGKPGRRGRAG & DQ2, DQ6, I-A(b) \\
p909 & RGQRGPTGPRGERGP & DQ2, DQ6, I-A(b) \\
\hline
\end{tabular}

The peptides bound by DR1 and DR15 and the DR17 and DR15-associated DQ alleles DQ2 (DQA1*0501: DQB1*0201) and DQ6 (DQA1*0102: DQB1*0602) and by the HLA-DQ homologue in B6 mice, I-A(b), are also shown. No peptides were found to bind to DR17 [34•]

response were dependent on P2X7R. Importantly, this receptor has non-redundant functions on both $\mathrm{T}$ cells and monocytes, P2X7Rs of both being required for the ColV response [38••]. ColV or ColV peptides both induced IL1 $\beta$ and TNF $\alpha$ in monocytes within the whole peripheral blood monoculear cell (PBMC) population after overnight stimulation. But, with isolated monocyte populations, only ColV but not synthetic ColV $\alpha 1$ peptides could induce IL1 $\beta$ and TNF $\alpha$ within the cells. This finding suggests that while ColV peptides can trigger $\mathrm{T}$ cells in whole PBMC to activate the monocytes, only ColV with all its tertiary structure and post-translational modifications [39•] can provide a damage-associated molecular pattern (DAMP) recognized by isolated monocytes [38••]. In addition to P2X7R, we have also found a striking difference in the role of leukocyte-associated immunoglobulin-like receptor 1 (LAIR1) in ColV responses [40]. In the current literature, which stems from in vitro data, LAIR1 is known to induce a potent inhibitory signal in cells [41]. However, our in vivo data suggest that LAIR1 might actually be required for mounting a $\mathrm{T}_{\mathrm{h}}$ 17-based immune response (Agashe et al. 2015 unpublished data/manuscript in preparation).

Besides its critical role in the chronic rejection of lung transplant rejection, ColV is also important in other pathology types such as PGD, bleomycin-induced pulmonary fibrosis, and atherosclerosis.

PGD is the most common early post-transplant complication following lung transplantation. Patients with PGD have an overall increased level of cytokines, and several studies have shown that PGD is associated with the development of BOS and thus negatively related to long-term graft survival [42-45]. Two papers in 2008 established the role of ColV in PGD. Bobadilla et al. [46] showed that $55 \%$ of the lung transplant patients who demonstrated ColV reactivity pretransplant developed PGD as compared to $21 \%$ of ColV non-responders. Poor graft function was significant at 6, 24, and 72 -h post-transplant. Similar results were also seen in a rat lung transplant model. Rats immunized with ColV pretransplant had lower lung function and an increased infiltration of mononuclear cells into the transplanted graft. It is, however, interesting to note that ColV-associated damage was only seen in the transplanted lung and not the native lung [47]. In addition to cellular immunity against ColV, humoral immunity has also been found to be important in PGD. Serum or splenic B cells from ColV-immunized rats could also induce pathology in rat lung isografts. Additionally, ColV antibodies were found to spike in patients with PGD and could be detected within 24-h post-transplant [47]. It is interesting to note that these antibodies were detected very early and possibly hint toward the existence of preformed ColV-specific B memory cells.

Similar to the results seen in lung patients, ColV response was also detected in patients with coronary artery disease (CAD). This response was dependent on $\mathrm{CD}^{+} \mathrm{T}_{\mathrm{h}}$ cells, along with IL17, IL22, IL1 $\beta$, and TNF $\alpha$. Similar results were also obtained in a murine model of atherosclerosis using ApoE ${ }^{-/-}$ mice fed a high-fat diet, and sensitization of mice with ColV exacerbated the disease [35]. Interestingly, $\mathrm{ApoE}^{-/}$mice fed normal chow developed an IL10-regulated response to ColV, suggesting the existence of natural control mechanisms at work to contain this response.

In the bleomycin-induced pulmonary fibrosis model, pretreatment of mice with ColV before bleomycin instillation reduced inflammation and the number of lymphocytes in the BAL specimen, along with a reduction in the number of lesions in the organ [48].

\section{K $\alpha 1$ tubulin in Lung Transplantation}

Research in the field of $K \alpha 1$ tubulin autoimmunity has its roots in the search for de novo donor-specific antibodies (DSAs) in patients with BOS. Most of the patients who develop chronic rejection also develop DSAs; however, many lung transplant patients with BOS did not demonstrate DSA. Such patients, however, had antibodies to non-HLA epithelial cells [5]. This suggested additional players in the development of BOS. Support for this came from animal model studies. The transfer of ColV immune serum into lung isograft recipients induced complement-mediated cytotoxicity on epithelial cells [47]. When serum from patients with BOS was incubated with AECs, antibodies were found to bind preferentially to a protein on/in these cells. Further analysis of this binding identified the protein to be $\mathrm{K} \alpha 1$ tubulin [5]. The authors subsequently showed that binding of these antibodies leads to the upregulation of growth factors such as epidermal growth factor (EGF), basic fibroblast growth factor (bFGF), and endothelin-1 (ET-1). All of these led to the fibroproliferation and subsequent 
BOS [30, 49]. Similar to ColV, pre-transplant antibodies to $\mathrm{K} \alpha 1$ tubulin are also a risk factor for PGD as well as BOS post-transplant [28, 29]. The up-regulation in these growth factors was mediated by the induction of HIF-1- $\alpha$, through the MAP kinase pathway [50]. K $\alpha 1$ tubulin usually remains sequestered within the cell or within the gap junction. Similar to ColV, K $\alpha 1$ tubulin has also been found within the lung tissue following lung transplantation (Dr. Mohanakumar, personal communication).

\section{Vimentin in Cardiac and Kidney Transplantation}

Anti-vimentin antibodies were found in patients following cardiac transplantation [51]. Subsequently, reports have shown the development of anti-vimentin antibodies in nonhuman primate cardiac allograft recipients. The authors failed to conclusively prove a link between anti-vimentin antibodies and the development of cardiac allograft vasculopathy (CAV) in these recipients [52]. However, reports have also shown an autoimmune response against vimentin in two murine models of CAV, which leads to an accelerated progression of CAV and subsequent rejection in these models. The recipient mice were immunized with vimentin and then transplanted with a minor mismatch cardiac allograft. The authors have demonstrated increased occlusion in the cardiac vessels and increased $\mathrm{C} 3 \mathrm{~d}$ deposition in the allograft. Interestingly, the authors did not see any such effect when isografts were used in place of allografts $[53,54]$. This difference in heart and lung isografts is intriguing. ColV reactivity eventually leads to the rejection of the isograft; however, vimentin reactivity did not. One line of hypothesis could be that lung tissue is continuously in contact with the outside environment, whereas the heart is not. The additional stress imposed by this could potentiate the ColV responses, and this, together with the anti-vimentin response, could possibly explain these differences.

Vimentin-reactive $\mathrm{CD}^{+}{ }^{+}$T cells have been demonstrated in patients after cardiac transplantation [55]. Renal transplant patients with graft failures also demonstrated anti-vimentin antibodies, before and at the time of graft failure [56]. Additionally, anti-vimentin antibodies have been found in nonhuman primate kidney transplants [57].

In contrast to anti-vimentin antibody studies, very little is known about cellular immune responses against vimentin. In a recent paper [58], the authors have implicated $\mathrm{CD}^{+} \mathrm{T}$ cells producing IL5 and IL17 in the development of antibodies against both cardiac myosin and vimentin in acute antibodymediated rejection (AMR) and $\mathrm{CAV}$, respectively. However, the authors failed to provide any direct evidence of $\mathrm{CD}^{+} \mathrm{T}$ cell involvement in myosin or vimentin autoreactivity [58]. Thus, the role of $\mathrm{CD}^{+} \mathrm{T}$ cells in vimentin autoreactivity remains ill-defined and warrants further investigation.

\section{Responses to Sequestered Self-Antigens: Are We Predisposed to React to Certain Self-Proteins and Why?}

Recent developments in the field of lung transplant autoimmunity have provided new answers to some pertinent, unanswered questions in the field of transplantation.

The recent paper by Subramanian et al., 2014, has put forth an intriguing hypothesis. The authors used a murine model of syngeneic left lung transplantation. Animals at the time of transplantation were administered preformed antibodies to either ColV or K $\alpha 1$ tubulin, alone or in combination. The authors reported both airway inflammation as well as fibrosis of only the transplanted lung at 45-days post-transplant. They demonstrated both a T cell and a B cell response against ColV and $K \alpha 1$ tubulin, irrespective of whether the animal received only anti-ColV antibodies or only anti K $\alpha 1$ tubulin antibodies or both. To explain this phenomenon, the authors put forth the membrane hypothesis. They hypothesized that administration of these antibodies somehow leads to the opsonization of membranes, which expressed these antigens. The subsequent engulfment of these membranes exposed the immune system to other antigens present on the membrane leading to epitope spreading between the two proteins of interest.

However, the authors demonstrated a response to both antigens at day 7 post-transplant but failed to explain the decreased time frame for this response [37••]. Similar issues were also noted in the editorial to this article [59]. Additionally, this contradicts the previous observations by the same group that alloimmunity precedes autoimmunity $[26,29]$.

Based on these observations, we can postulate that ColVreactive $T_{h} 17$ cells develop in the periphery from naïve T cells (Fig. 1). Tissue injury leads to enhanced or irregular expression of proteins such as ColV or K $\alpha 1$ tubulin. These proteins are then picked up by antigen-presenting cells (APCs) and exposed to $\mathrm{T}$ cells within the peripheral lymphoid system. Under normal conditions, such a response is beneficial to the host as it can induce tissue repair and healing through the production of IL17 and IL22 and subsequent memory $\mathrm{T}_{\text {reg }}$ cell generation. However, following lung or heart transplantation, there is a prolonged exposure to antigens such as ColV or K $\alpha 1$ tubulin. Due to this prolonged exposure, the $\mathrm{T}_{\text {reg }}$ can no longer maintain the $\mathrm{T}_{\text {eff }}$ cells, ultimately resulting in the development of autoimmunity (Fig. 1).

However, we have recently found a possible explanation for why the opposite may be the case - that autoimmunity might actually precede alloimmunity in organ transplantation - and for why reactivity to certain self antigens may be particularly favored (e.g., ColV and $\mathrm{K} \alpha 1$ tubulin after lung transplantation) and others (ColI, ColII, and ColIV) may not be. This explanation comes from a recent work in our lab. We noted that, in the past 6 years, the role of CD $39^{+} \mathrm{T}_{\text {reg }}$ controlling $\mathrm{T}_{\mathrm{h}}$ 17-mediated effector function in a number of 


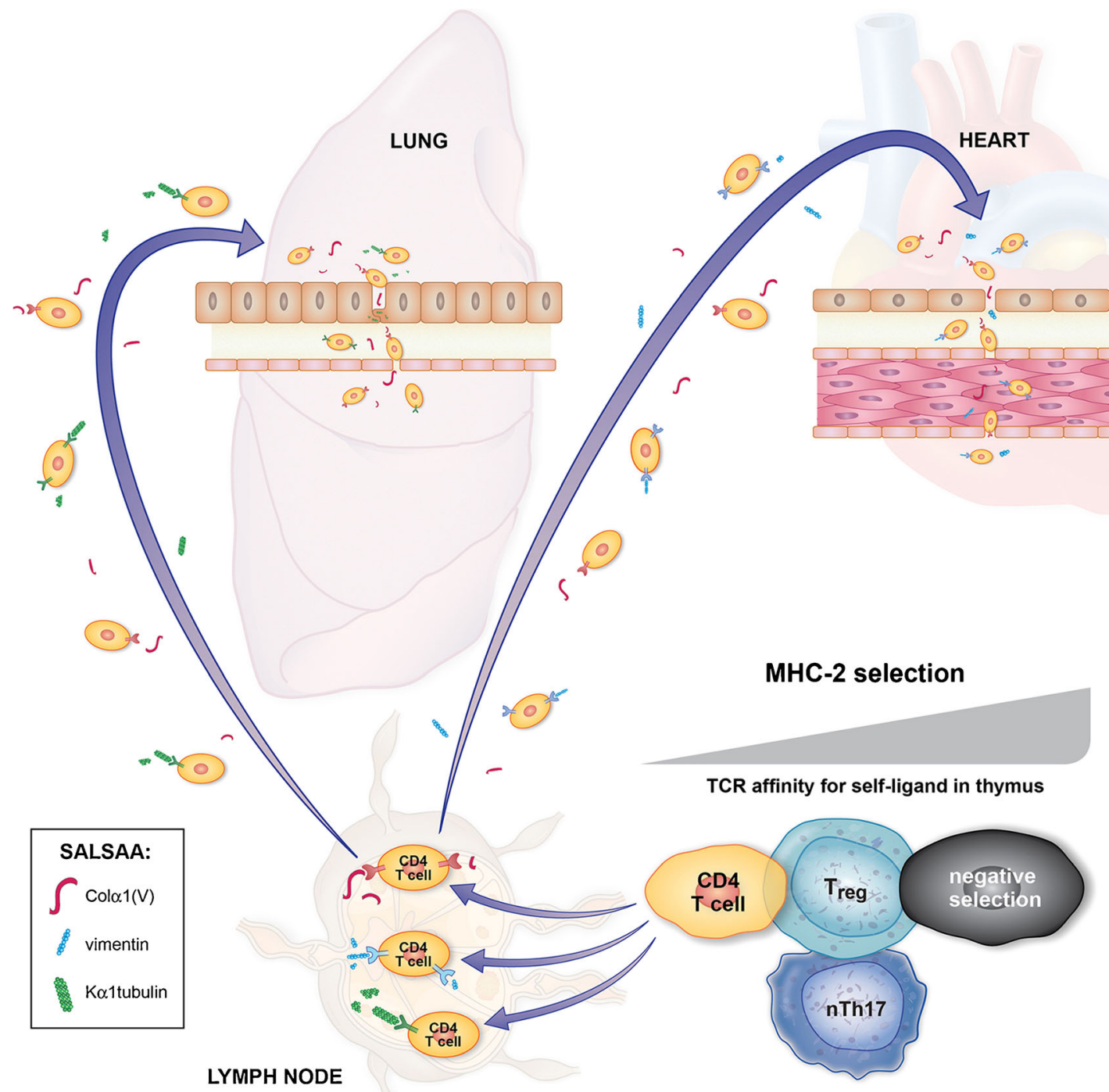

Fig. 1 Hypothetical model 1 for the development of autoimmunity following lung or heart transplantation. The antigen-specific T cells are induced in the periphery. Following tissue injury, naïve T cells (yellow) emerge from the thymus and are exposed in the peripheral lymph node to sequestered self-antigens such as ColV (red), vimentin (blue), or $\mathrm{K} \alpha 1$ tubulin (green). This exposure could potentially give rise to both $\mathrm{T}_{\text {eff }}$ and $\mathrm{T}_{\text {reg }}$ cells in the periphery. Under these conditions, such cells help in restoring epithelial barrier integrity and help resolve the injury. However, in cases of prolonged injury, such as transplant/surgery, recurrent viral infection, or anti-HLA response, the matrix proteins break down, exposing sequestered antigens continuously. The $\mathrm{T}_{\text {reg }}$ cells can then no longer maintain a balance and a full-blown immune response results autoimmune diseases including lupus, multiple sclerosis, and transplant-related pathology has emerged [38••, 60-63]. We found that normal individuals become reactive to certain selfantigens, including ColV, $\mathrm{K} \alpha 1$ tubulin, and vimentin simply by removal of $\mathrm{CD} 9^{+} \mathrm{T}$ cells in a $\mathrm{T}_{\mathrm{h}} 17$-dependent fashion. This $\mathrm{T}_{\mathrm{h}} 17$ response, observed after $\mathrm{CD} 39^{+} \mathrm{T}_{\text {reg }}$ cell depletion, was not seen with ColI, cardiac myosin, prostrate acid phosphatase, or myelin basic protein (Sullivan et al. 2015, unpublished data/manuscript in preparation). Additionally, this uncovered response to self-antigens was also observed following the removal of $\mathrm{CD} 25^{+} \mathrm{T}$ cells, inhibition of the $\mathrm{CD} 39$ extracellular ATPase activity, or neutralization of TGF $\beta$ or IL35 cytokine. Thus, recent data imply a strong regulatory balance between $\mathrm{CD} 39^{+} \mathrm{T}_{\text {reg }}$ and $\mathrm{ColV}, \mathrm{K} \alpha 1$ tubulin, and vimentin effector $T_{h} 17$ cells in normal healthy individuals. This observation was confirmed in non-human primates and in CBA mice. However, it is important to note that very little response to ColV was seen in normal B6 mice splenocytes with IL10 or TGF $\beta$ neutralizations [35] (Sullivan et al. 2015 unpublished data/manuscript in preparation). This difference between the human samples and mouse data thus warrants further investigation. However, such discrepancies are also seen with responses against ColV; IL22 plays a role in ColV and ColV peptide-specific $T_{h} 17$ reactivity in humans; however, IL22 
had no role in responses against ColV $\alpha 1$ peptide p599 in the B6 mouse (Agashe et al. unpublished observations).

Thus, recent developments in the field would take this a step further and argue that every individual is predisposed to respond to certain self-antigens and that there is a very fine balance between regulation and development of autoimmunity (Fig. 2). Thus, we all have a very small pool of self-reactive $\mathrm{T}$ cells, which in normal healthy individuals remain in a fine balance with $\mathrm{CD} 39^{+} \mathrm{T}_{\text {reg }}$ cells (Fig. 2: STEP 1 and STEP 2). The origins of these cells are topics still under investigation. Nonetheless, one could argue that such cells are actually required for maintaining homeostasis; a small injury, which may result in the release of these self-antigens, is potentially beneficial for the immune system. These cells could easily recognize these proteins and could induce a beneficial resolving response leading to tissue repair. This would also explain another key piece in autoimmunity. Why do we see such a $T_{h} 17$ bias in autoimmune diseases? If indeed these self-reactive cells are present for homeostasis, then the role of IL17 and subsequent IL22 becomes very obvious. These two cytokines are important in maintaining epithelial membrane integrity.

However, a major surgical procedure, such as transplantation in which these proteins are overexposed, creates an environment more suited to the development of autoimmunity owing in part to the continued use of immunosuppressants. Evidence also exists that after transplantation it is only the transplanted lung that is affected, whereas the native remains intact $[12,37 \bullet \bullet, 47]$. Thus, it is interesting to hypothesize that the IRI during the course of transplantation predisposes the patients to a disrupted extracellular matrix, fibroproliferation,

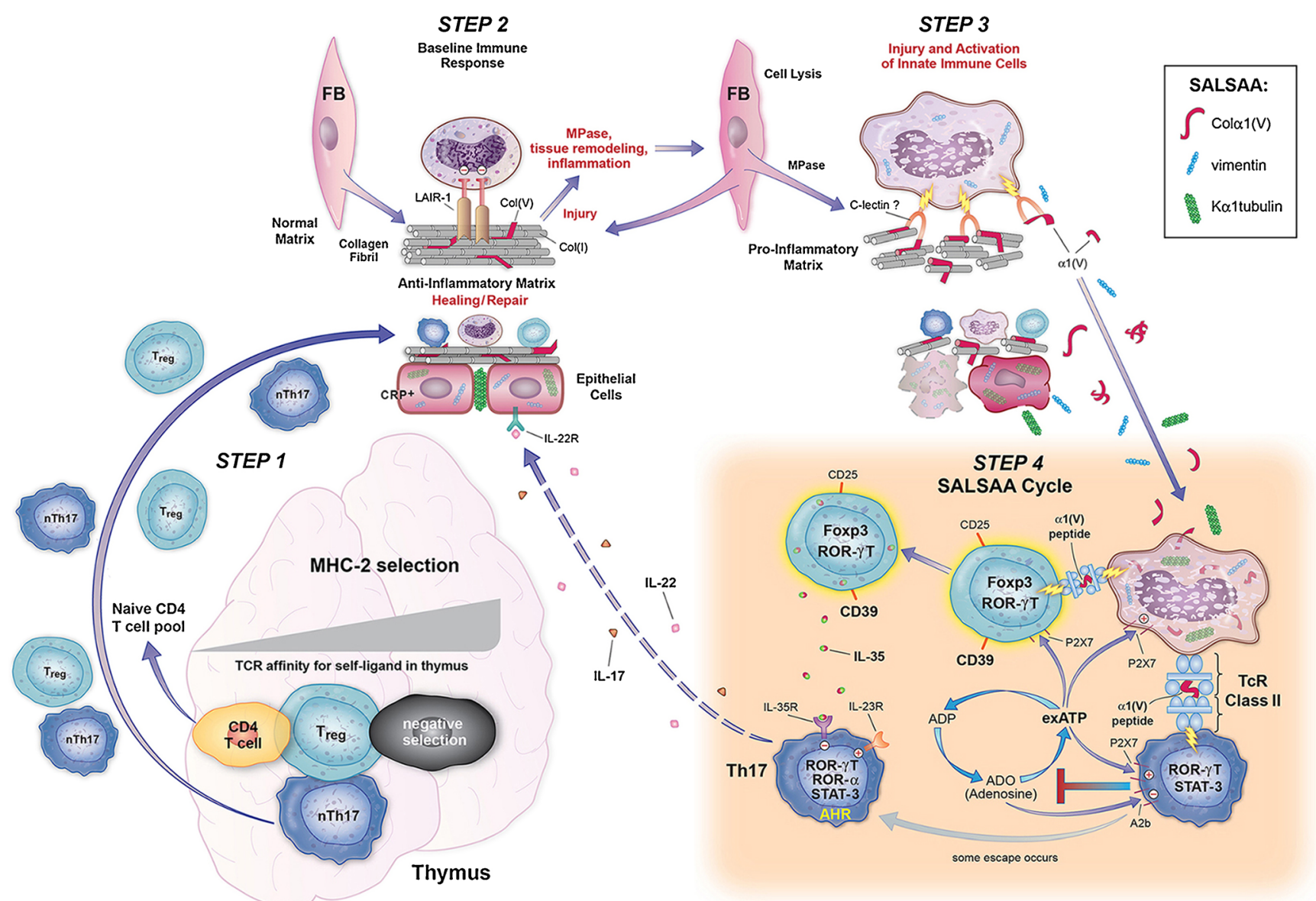

Fig. 2 Hypothetical model 2 for the development of autoimmunity following lung transplantation. Within the periphery, there already exist some natural $\mathrm{T}_{\mathrm{h}} 17\left(\mathrm{nT}_{\mathrm{h}} 17\right) \mathrm{CD}^{+}$cells as well as $\mathrm{nT}_{\text {regs }}$ specific for selfpeptides that emerge from the thymus with a memory phenotype (STEP 1). In this view, T cells specific for ColV (red), vimentin (blue), or K $\alpha 1$ tubulin (green) are not exposed in the periphery but are selected for these particular reactivities before leaving the thymus. Preliminary data from the Burlingham lab support this possibility. $T_{h} 17$ cells specific to all three SALSAAs but not to ColI were found in the human 17-week fetal thymus, cord blood, and in the peripheral blood of all healthy adults (Sullivan et al. 2015, unpublished data/manuscript in preparation).
Under quiescent conditions, these cells do not encounter their cognate antigen and remain in homeostasis with $\mathrm{CD} 39^{+} \mathrm{T}_{\text {reg }}$ cells in the periphery. After minor injury, they may play an important role in restoring epithelial/ endothelial barrier integrity, possibly through their production of IL22 as well as IL17 (STEP 2). However, in cases of prolonged injury such as transplant/surgery, the matrix proteins constantly break down or abnormal forms of these three proteins are made, exposing sequestered antigens such as ColV or K $\alpha 1$ tubulin (STEP 3). The recipient CD39 ${ }^{+} \mathrm{T}_{\text {reg }}$ cells can no longer maintain a balance with the $\mathrm{nT}_{\mathrm{h}} 17$ which are both donor as well as recipient-derived, leading to a full-blown immune response against self-antigens following transplantation (STEP 4) 
and formation of irregular collagen fibrils, e.g., ColV $\alpha 1$ homotrimers. All of this ultimately results in the induction of autoimmunity following transplantation. Under these circumstances, IL17 becomes a predominant player as compared to IL22 resulting in the induction of autoimmunity (Fig. 2: STEP 3 and STEP 4).

One last aspect to be considered is whether such a response can be classified as an autoimmune response. In order to function properly, the recipient immune system has to maintain a fine balance between the donor and recipient DR. However, in most circumstances, the recipient immune system cannot be regulated to the donor DR or to self-peptides presented by donor DR, thus possibly exposing a weakness in $\mathrm{T}_{\text {reg }}$ control of immune responses against ColV, $\mathrm{K} \alpha 1$ tubulin, or vimentin.

Thus, current developments in this field argue against autoimmunity as merely a bystander in an otherwise alloimmune response. If indeed it were a mere bystander, we will not expect autoimmunity to lead to graft destruction, loss, and subsequent death of the recipient $[12,37 \bullet \bullet, 64]$. Autoimmunity is indeed an important player in chronic rejection and is supported by the fact that autoimmunity by itself can lead to chronic rejection which, in turn, leads to graft loss and death [4]. This supports the hypothesis that autoimmunity plays an active role in mediating rejection, especially chronic rejection.

\section{Autoimmunity in Organ Transplantation in the $T_{h} 1 / T_{h} 2$ Era}

\section{Cardiac Myosin and Hsps in Cardiac Transplantation}

Prior to the discovery of IL23 and $T_{h} 17$ cells, research in the field of transplantation had focused on the $\mathrm{T}_{\mathrm{h}} 1$ and $\mathrm{T}_{\mathrm{h}} 2$ cells as the major players in transplant immunology [65-67]. During these early studies of autoimmunity in transplantation, it was demonstrated that alloimmune response could potentially induce an autoimmune response in mice receiving allogeneic cells [68].

Later, the same authors conclusively demonstrated the role of cardiac myosin in the rejection of cardiac transplants. Mice receiving allogeneic but not syngeneic hearts had cardiacmyosin-reactive $T_{h} 1$ cells producing IFN $\gamma$ and anti-myosin antibodies. However, the authors also demonstrated that active immunizations of recipient mice with cardiac myosin not only lead to a faster allogeneic graft loss but also lead to a chronic rejection and subsequent loss of syngeneic hearts. It is important to note that the native hearts in these mice showed very little signs of pathology [69]. These observations support the hypothesis that the immune response toward self-antigens is highly regulated and only a trauma (surgery or IRI) or injury (immunizations) shifts this response toward a pathologic one $[69,70]$.
Additional studies emphasized the role of direct and indirect alloimmunity in the development of cardiac myosin autoimmunity following cardiac transplantation [71]. It was demonstrated that a $\mathrm{T}_{\mathrm{h}}$ 2-biased cardiac myosin response prevented the acute rejection of a graft from an Major Histocompatibility Complex (MHC) I disparate donor but failed to prevent the rejection in an MHC II major mismatch model. However, when an MHC II knockout donor graft was used, the $\mathrm{T}_{\mathrm{h}} 2$ biased cardiac myosin response prolonged the graft survival [72]. Mice were also treated with MR1 (anti-CD40L) at the time of cardiac transplantation. Introduction of MR1 is known to prolong graft survival in a major mismatch model of cardiac transplantation but does not prevent graft loss due to chronic rejection. Thus, at the time of rejection, animals treated with MR1 demonstrated a low alloimmune response against the donor but a robust response against cardiac myosin. The graft loss was attributed to this autoimmune response. However, it is important to note that the level of response to cardiac myosin was lower as compared to untreated controls. The authors postulated the presence of two distinct populations of autoreactive $T$ cells, one which developed from naïve cells and had a stringent dependency on CD40-CD40L co-stimulation and a second cell with a memory phenotype with lower dependency on CD40-CD40L co-stimulation [64]. This supports our hypothesis that we all have a small pool of selfreactive memory cells within our immune system.

A major drawback of these studies is the fact that the authors only focused on the $T_{h} 1$ and $T_{h} 2$ cells. With the recent developments in the field of $\mathrm{T}_{h} 17, \mathrm{~T}_{\mathrm{h}} 17 / 1$ [73•], and $\mathrm{T}_{\text {reg }}$ cells, it will be interesting to go back and determine the role of these cells in the autoimmune response to cardiac myosin.

More recently, $\mathrm{T}$ and $\mathrm{B}$ cell responses against cardiac myosin have also been detected in CAV patients. Depletion of $\mathrm{CD}_{25} 5^{+}$FoxP $^{+} \mathrm{T}_{\text {reg }}$ cells from the PBMC population of myosin responders enhanced their response to cardiac myosin. However, such a strategy did not uncover any response in the myosin non-responders [74]. This phenomenon fits in quite well with our hypothesis that there are few antigens that, which for some reason, we are programmed to respond to and that remain in a tight regulation within a normal healthy individual.

Early evidence for the role of Hsps in cardiac transplantation came during the 1990s. The work by Moliterno et al. in 1995 showed that Hsps from Mycobacterium tuberculosis extract induced the proliferation of lymphocytes from cardiac transplant patients undergoing rejection. This was one the early reports showing Hsp65 as a potential autoantigen in cardiac transplantation [75]. These results were further studied using a cardiac transplant model in rats, which also demonstrated Hsp reactivity [76]. Graft infiltrating and splenic lymphocytes from the recipient were cultured with Hsp65 and Hsp70, along with irradiated donor cells. The authors showed an augmentation of the alloresponse in the presence of Hsp65 and Hsp70. 
Surprising recipient cells by themselves did not respond to any of the Hsps tested. This indicated that there was a donor dependency with Hsp reactivity [77]. Later, other Hsps were also found to be important in cardiac transplantation, such as Hsp60. Patients with pre-transplant anti-Hsp60 antibodies had a worse prognosis following cardiac transplantation [78]. Interestingly enough, some other Hsps have been found to have a protective effect in cardiac transplantation [79]. Thus, the role of Hsps still requires further investigation.

\section{Conclusions}

In conclusion, data exist to support the hypothesis that autoimmunity plays an important role in chronic rejection. Autoimmunity has been linked to the development of chronic rejection and subsequently graft loss in several organ transplant settings. However, the origins and mechanisms of autoimmunity after transplantation still require further investigation. Along with this, further studies are needed to determine how we can therapeutically target the response against these selfantigens, the P2X7R being one such target, with the ultimate goal being long-term graft survival without the development of chronic rejection.

\section{Compliance with Ethics Guidelines}

Conflict of Interest Vrushali V. Agashe and William J. Burlingham declare that they have no conflict of interest.

Human and Animal Rights and Informed Consent This article does review studies with human or animal subjects; these studies were performed in compliance with human subject/IRB and vertebrate animal/ IACUC guidelines.

\section{References}

Papers of particular interest, published recently, have been highlighted as:

- Of importance

•- Of major importance

1. Estenne M, Maurer JR, Boehler A, Egan JJ, Frost A, Hertz M, et al. Bronchiolitis obliterans syndrome 2001: an update of the diagnostic criteria. J Heart Lung Transplant. 2002;21(3):297-310.

2. Yusen RD, Christie JD, Edwards LB, Kucheryavaya AY, Benden C, Dipchand AI, et al. The Registry of the International Society for Heart and Lung Transplantation: Thirtieth Adult Lung and HeartLung Transplant Report-2013; focus theme: age. J Heart Lung Transplant. 2013;32(10):965-78.

3. Lund LH, Edwards LB, Kucheryavaya AY, Dipchand AI, Benden C, Christie JD, et al. The Registry of the International Society for Heart and Lung Transplantation: Thirtieth Official Adult Heart
Transplant Report-2013; focus theme: age. J Heart Lung Transplant. 2013;32(10):951-64.

4. Burlingham WJ, Love RB, Jankowska-Gan E, Haynes LD, Xu Q, Bobadilla JL, et al. IL-17-dependent cellular immunity to collagen type $\mathrm{V}$ predisposes to obliterative bronchiolitis in human lung transplants. J Clin Invest. 2007;117(11):3498-506.

5. Goers TA, Ramachandran S, Aloush A, Trulock E, Patterson GA, Mohanakumar T. De novo production of K-alphal tubulin-specific antibodies: role in chronic lung allograft rejection. J Immunol. 2008;180(7):4487-94.

6. Birk DE, Fitch JM, Babiarz JP, Linsenmayer TF. Collagen type I and type $V$ are present in the same fibril in the avian corneal stroma. J Cell Biol. 1988;106(3):999-1008.

7. Linsenmayer TF, Gibney E, Igoe F, Gordon MK, Fitch JM, Fessler LI, et al. Type V collagen: molecular structure and fibrillar organization of the chicken alpha $1(\mathrm{~V}) \mathrm{NH} 2$-terminal domain, a putative regulator of corneal fibrillogenesis. J Cell Biol. 1993;121(5):11819.

8. Konomi H, Hayashi T, Nakayasu K, Arima M. Localization of type $\mathrm{V}$ collagen and type IV collagen in human cornea, lung, and skin. Immunohistochemical evidence by anti-collagen antibodies characterized by immunoelectroblotting. Am J Pathol. 1984;116(3):41726.

9. Madri JA, Furthmayr H. Isolation and tissue localization of type AB2 collagen from normal lung parenchyma. Am J Pathol. 1979;94(2):323-31.

10. Madri JA, Furthmayr H. Collagen polymorphism in the lung. An immunochemical study of pulmonary fibrosis. Hum Pathol. 1980;11(4):353-66.

11. Fitch JM, Birk DE, Mentzer A, Hasty KA, Mainardi C, Linsenmayer TF. Corneal collagen fibrils: dissection with specific collagenases and monoclonal antibodies. Invest Ophthalmol Vis Sci. 1988;29(7):1125-36.

12. Yoshida S, Haque A, Mizobuchi T, Iwata T, Chiyo M, Webb TJ, et al. Anti-type V collagen lymphocytes that express IL-17 and IL23 induce rejection pathology in fresh and well-healed lung transplants. Am J Transplant. 2006;6(4):724-35.

13. Vittal R, Fan L, Greenspan DS, Mickler EA, Gopalakrishnan B, Gu $\mathrm{H}$, et al. IL-17 induces type V collagen overexpression and EMT via TGF-beta-dependent pathways in obliterative bronchiolitis. Am J Physiol Lung Cell Mol Physiol. 2013;304(6):L401-14.

14. Giepmans BN, Verlaan I, Hengeveld T, Janssen H, Calafat J, Falk $\mathrm{MM}$, et al. Gap junction protein connexin-43 interacts directly with microtubules. Curr Biol. 2001;11(17):1364-8.

15. Barefield D, Sadayappan S. Phosphorylation and function of cardiac myosin binding protein- $\mathrm{C}$ in health and disease. $\mathrm{J}$ Mol Cell Cardiol. 2010;48(5):866-75.

16. Dave JM, Bayless KJ. Vimentin as an integral regulator of cell adhesion and endothelial sprouting. Microcirculation. 2014;21(4): 333-44.

17. Mor-Vaknin N, Punturieri A, Sitwala K, Markovitz DM. Vimentin is secreted by activated macrophages. Nat Cell Biol. 2003;5(1):5963.

18. Binder RJ. Functions of heat shock proteins in pathways of the innate and adaptive immune system. J Immunol. 2014;193(12): 5765-71.

19. Wilkes DS, Heidler KM, Niemeier M, Schwenk GR, Mathur PN, Breite WM, et al. Increased bronchoalveolar IgG2/IgG1 ratio is a marker for human lung allograft rejection. J Investig Med. 1994;42(4):652-9.

20. Wilkes DS, Heidler KM, Bowen LK, Quinlan WM, Doyle NA, Cummings OW, et al. Allogeneic bronchoalveolar lavage cells induce the histology of acute lung allograft rejection, and deposition of IgG2a in recipient murine lungs. J Immunol. 1995;155(5): 2775-83. 
21. Mares DC, Heidler KM, Smith GN, Cummings OW, Harris ER, Foresman B, et al. Type $\mathrm{V}$ collagen modulates alloantigen-induced pathology and immunology in the lung. Am J Respir Cell Mol Biol. 2000;23(1):62-70.

22. Yasufuku K, Heidler KM, O’Donnell PW, Smith Jr GN, Cummings $\mathrm{OW}$, Foresman $\mathrm{BH}$, et al. Oral tolerance induction by type $\mathrm{V}$ collagen down regulates lung allograft rejection. Am J Respir Cell Mol Biol. 2001;25(1):26-34.

23. Yasufuku K, Heidler KM, Woods KA, Smith Jr GN, Cummings OW, Fujisawa T, et al. Prevention of bronchiolitis obliterans in rat lung allografts by type $\mathrm{V}$ collagen-induced oral tolerance. Transplantation. 2002;73(4):500-5.

24. Haque MA, Mizobuchi T, Yasufuku K, Fujisawa T, Brutkiewicz RR, Zheng Y, et al. Evidence for immune responses to a selfantigen in lung transplantation: role of type $\mathrm{V}$ collagen-specific $\mathrm{T}$ cells in the pathogenesis of lung allograft rejection. J Immunol. 2002;169(3):1542-9.

25. Braun RK, Molitor-Dart M, Wigfield C, Xiang Z, Fain SB, Jankowska-Gan E, et al. Transfer of tolerance to collagen type V suppresses T-helper-cell-17 lymphocyte-mediated acute lung transplant rejection. Transplantation. 2009;88(12):1341-8.

26. Fukami N, Ramachandran S, Saini D, Walter M, Chapman W, Patterson GA, et al. Antibodies to MHC class I induce autoimmunity: role in the pathogenesis of chronic rejection. $\mathrm{J}$ Immunol. 2009;182(1):309-18.

27. Smith CR, Jaramillo A, Lu KC, Higuchi T, Kaleem Z, Mohanakumar T. Prevention of obliterative airway disease in HLA-A2-transgenic tracheal allografts by neutralization of tumor necrosis factor. Transplantation. 2001;72(9):1512-8.

28. Bharat A, Saini D, Steward N, Hachem R, Trulock EP, Patterson GA, et al. Antibodies to self-antigens predispose to primary lung allograft dysfunction and chronic rejection. Ann Thorac Surg. 2010;90(4):1094-101.

29. Saini D, Weber J, Ramachandran S, Phelan D, Tiriveedhi V, Liu M, et al. Alloimmunity-induced autoimmunity as a potential mechanism in the pathogenesis of chronic rejection of human lung allografts. J Heart Lung Transplant. 2011;30(6):624-31.

30. Hachem RR, Tiriveedhi V, Patterson GA, Aloush A, Trulock EP, Mohanakumar T. Antibodies to K-alpha 1 tubulin and collagen V are associated with chronic rejection after lung transplantation. Am J Transplant. 2012;12(8):2164-71.

31. Vittal R, Mickler EA, Fisher AJ, Zhang C, Rothhaar K, Gu H, et al. Type $\mathrm{V}$ collagen induced tolerance suppresses collagen deposition, TGF-beta and associated transcripts in pulmonary fibrosis. PLoS ONE. 2013;8(10):e76451.

32. Fan L, Benson HL, Vittal R, Mickler EA, Presson R, Fisher AJ, et al. Neutralizing IL-17 prevents obliterative bronchiolitis in murine orthotopic lung transplantation. Am J Transplant. 2011;11(5): 911-22.

33. Suzuki H, Lasbury ME, Fan L, Vittal R, Mickler EA, Benson HL, et al. Role of complement activation in obliterative bronchiolitis post-lung transplantation. J Immunol. 2013;191(8):4431-9.

34. Keller MR, Haynes LD, Jankowska-Gan E, Sullivan JA, Agashe VV, Burlingham SR, et al. Epitope analysis of the collagen type Vspecific $T$ cell response in lung transplantation reveals an HLADRB $1 * 15$ bias in both recipient and donor. PLoS ONE. 2013;8(11):e79601. This paper describes the DR bias in Collagen Type $V$ autoimmunity and identified several peptides/epitopes of Collagen Type $\mathrm{V}$.

35. Dart ML, Jankowska-Gan E, Huang G, Roenneburg DA, Keller MR, Torrealba JR, et al. Interleukin-17-dependent autoimmunity to collagen type V in atherosclerosis. Circ Res. 2010;107(9): 1106-16.

36. Tiriveedhi V, Angaswamy N, Brand D, Weber J, Gelman AG, Hachem R, et al. A shift in the collagen V antigenic epitope leads to $\mathrm{T}$ helper phenotype switch and immune response to self-antigen leading to chronic lung allograft rejection. Clin Exp Immunol. 2012;167(1):158-68.

37.• Subramanian V, Ramachandran S, Banan B, Bharat A, Wang X, Benshoff $\mathrm{N}$, et al. Immune response to tissue-restricted self-antigens induces airway inflammation and fibrosis following murine lung transplantation. Am J Transplant. 2014;14(10):2359-66. This paper describes epitope spreading between the two important autoantigens in lung transplantation, Collagen Type $\mathrm{V}$ and $\mathrm{K}$ $\alpha$-tubulin.

38.• Sullivan JA, Jankowska-Gan E, Shi L, Roenneburg D, Hegde S, Greenspan DS, et al. Differential requirement for P2X7R function in IL-17 dependent vs. IL-17 independent cellular immune responses. Am J Transplant. 2014;14(7):1512-22. This paper describes the importance of the $\mathrm{P} 2 \mathrm{X} 7$ receptor in $\mathrm{Th} 17$ mediated Collagen Type $\mathrm{V}$ autoimmunity.

39. Yang C, Park AC, Davis NA, Russell JD, Kim B, Brand DD, et al. Comprehensive mass spectrometric mapping of the hydroxylated amino acid residues of the alpha1(V) collagen chain. J Biol Chem. 2012;287(48):40598-610. This paper describes the posttranslational modifications present on the $\alpha 1$ chain of the Collagen Type V molecule.

40. Meyaard L. The inhibitory collagen receptor LAIR-1 (CD305). J Leukoc Biol. 2008;83(4):799-803.

41. Meyaard L, Adema GJ, Chang C, Woollatt E, Sutherland GR, Lanier LL, et al. LAIR-1, a novel inhibitory receptor expressed on human mononuclear leukocytes. Immunity. 1997;7(2):283-90.

42. Daud SA, Yusen RD, Meyers BF, Chakinala MM, Walter MJ, Aloush AA, et al. Impact of immediate primary lung allograft dysfunction on bronchiolitis obliterans syndrome. Am J Respir Crit Care Med. 2007;175(5):507-13.

43. Huang HJ, Yusen RD, Meyers BF, Walter MJ, Mohanakumar T, Patterson GA, et al. Late primary graft dysfunction after lung transplantation and bronchiolitis obliterans syndrome. Am J Transplant. 2008;8(11):2454-62.

44. Whitson BA, Prekker ME, Herrington CS, Whelan TP, Radosevich DM, Hertz MI, et al. Primary graft dysfunction and long-term pulmonary function after lung transplantation. J Heart Lung Transplant. 2007;26(10):1004-11.

45. Bharat A, Kuo E, Steward N, Aloush A, Hachem R, Trulock EP, et al. Immunological link between primary graft dysfunction and chronic lung allograft rejection. Ann Thorac Surg. 2008;86(1):189 95 .

46. Bobadilla JL, Love RB, Jankowska-Gan E, Xu Q, Haynes LD, Braun RK, et al. Th-17, monokines, collagen type V, and primary graft dysfunction in lung transplantation. Am J Respir Crit Care Med. 2008;177(6):660-8.

47. Iwata T, Philipovskiy A, Fisher AJ, Presson Jr RG, Chiyo M, Lee J, et al. Anti-type V collagen humoral immunity in lung transplant primary graft dysfunction. J Immunol. 2008;181(8):5738-47.

48. Braun RK, Martin A, Shah S, Iwashima M, Medina M, Byrne K, et al. Inhibition of bleomycin-induced pulmonary fibrosis through pre-treatment with collagen type V. J Heart Lung Transplant. 2010;29(8):873-80.

49. Tiriveedhi V, Angaswamy N, Weber J, Mohanakumar T. Lipid raft facilitated ligation of K-alpha1-tubulin by specific antibodies on epithelial cells: role in pathogenesis of chronic rejection following human lung transplantation. Biochem Biophys Res Commun. 2010;399(2):251-5.

50. Tiriveedhi V, Gelman AE, Mohanakumar T. HIF-1alpha signaling by airway epithelial cell $\mathrm{K}$-alpha1-tubulin: role in fibrosis and chronic rejection of human lung allografts. Cell Immunol. 2012;273(1):59-66.

51. Jurcevic S, Ainsworth ME, Pomerance A, Smith JD, Robinson DR, Dunn MJ, et al. Antivimentin antibodies are an independent predictor of transplant-associated coronary artery disease after cardiac transplantation. Transplantation. 2001;71(7):886-92. 
52. Azimzadeh AM, Pfeiffer S, Wu GS, Schroder C, Zhou H, Zorn 3rd GL, et al. Humoral immunity to vimentin is associated with cardiac allograft injury in nonhuman primates. Am J Transplant. 2005;5(10):2349-59.

53. Mahesh B, Leong HS, McCormack A, Sarathchandra P, Holder A, Rose ML. Autoantibodies to vimentin cause accelerated rejection of cardiac allografts. Am J Pathol. 2007;170(4):1415-27.

54. Mahesh B, Leong HS, Nair KS, McCormack A, Sarathchandra P, Rose ML. Autoimmunity to vimentin potentiates graft vasculopathy in murine cardiac allografts. Transplantation. 2010;90(1):4-13.

55. Barber LD, Whitelegg A, Madrigal JA, Banner NR, Rose ML. Detection of vimentin-specific autoreactive CD8+ T cells in cardiac transplant patients. Transplantation. 2004;77(10):1604-9.

56. Carter V, Shenton BK, Jaques B, Turner D, Talbot D, Gupta A, et al. Vimentin antibodies: a non-HLA antibody as a potential risk factor in renal transplantation. Transplant Proc. 2005;37(2):654-7.

57. Jonker M, Danskine A, Haanstra K, Wubben J, Kondova I, Kuhn $\mathrm{EM}$, et al. The autoimmune response to vimentin after renal transplantation in nonhuman primates is immunosuppression dependent. Transplantation. 2005;80(3):385-93.

58. Nath DS, Ilias Basha H, Tiriveedhi V, Alur C, Phelan D, Ewald GA, et al. Characterization of immune responses to cardiac self-antigens myosin and vimentin in human cardiac allograft recipients with antibody-mediated rejection and cardiac allograft vasculopathy. $\mathrm{J}$ Heart Lung Transplant. 2010;29(11):1277-85.

59. Burlingham W, Wilkes DS, Sullivan JA. Why is the patient out of breath? Collagen V(alpha1) and K-alpha1-tubulin take center stage in lung transplantation. Am J Transplant. 2014;14(10):2201-3.

60. Loza MJ, Anderson AS, O'Rourke KS, Wood J, Khan IU. T-cell specific defect in expression of the NTPDase CD39 as a biomarker for lupus. Cell Immunol. 2011;271(1):110-7.

61. Fletcher JM, Lonergan R, Costelloe L, Kinsella K, Moran B, O'Farrelly C, et al. CD39+ Foxp3+ regulatory T cells suppress pathogenic Th17 cells and are impaired in multiple sclerosis. J Immunol. 2009;183(11):7602-10.

62. Peelen E, Damoiseaux J, Smolders J, Knippenberg S, Menheere P, Tervaert JW, et al. Th17 expansion in MS patients is counterbalanced by an expanded CD39+ regulatory T cell population during remission but not during relapse. J Neuroimmunol. 2011;240-241:97-103.

63. Wang YM, McRae JL, Robson SC, Cowan PJ, Zhang GY, Hu M, et al. Regulatory $\mathrm{T}$ cells participate in CD39-mediated protection from renal injury. Eur J Immunol. 2012;42(9):2441-51.

64. Rolls HK, Kishimoto K, Dong VM, Illigens BM, Sho M, Sayegh $\mathrm{MH}$, et al. T-cell response to cardiac myosin persists in the absence of an alloimmune response in recipients with chronic cardiac allograft rejection. Transplantation. 2002;74(7):1053-7.

65. Harrington LE, Hatton RD, Mangan PR, Turner H, Murphy TL, Murphy KM, et al. Interleukin 17-producing CD4+ effector T cells develop via a lineage distinct from the Thelper type 1 and 2 lineages. Nat Immunol. 2005;6(11):1123-32.
66. Park H, Li Z, Yang XO, Chang SH, Nurieva R, Wang YH, et al. A distinct lineage of CD4 $\mathrm{T}$ cells regulates tissue inflammation by producing interleukin 17. Nat Immunol. 2005;6(11):1133-41.

67. Cua DJ, Sherlock J, Chen Y, Murphy CA, Joyce B, Seymour B, et al. Interleukin-23 rather than interleukin-12 is the critical cytokine for autoimmune inflammation of the brain. Nature. 2003;421(6924):744-8.

68. Fedoseyeva EV, Tam RC, Popov IA, Orr PL, Garovoy MR, Benichou G. Induction of T cell responses to a self-antigen following allotransplantation. Transplantation. 1996;61(5):679-83.

69. Fedoseyeva EV, Zhang F, Orr PL, Levin D, Buncke HJ, Benichou G. De novo autoimmunity to cardiac myosin after heart transplantation and its contribution to the rejection process. J Immunol. 1999;162(11):6836-42.

70. Poindexter NJ, Steward NS, Shenoy S, Jendrisak MD, Flye MW, Howard TK, et al. Cytolytic T lymphocytes from human renal allograft biopsies are tissue specific. Hum Immunol. 1995;44(1): 43-9.

71. Rolls HK, Kishimoto K, Illigens BM, Dong V, Sayegh MH, Benichou G, et al. Detection of cardiac myosin-specific autoimmunity in a model of chronic heart allograft rejection. Transplant Proc. 2001;33(7-8):3821-2.

72. Fedoseyeva EV, Kishimoto K, Rolls HK, Illigens BM, Dong VM, Valujskikh A, et al. Modulation of tissue-specific immune response to cardiac myosin can prolong survival of allogeneic heart transplants. J Immunol. 2002;169(3):1168-74.

73. Sallusto F, Zielinski CE, Lanzavecchia A. Human Th17 subsets. Eur J Immunol. 2012;42(9):2215-20. This paper describes the development of Th17/1 cells.

74. Kalache S, Dinavahi R, Pinney S, Mehrotra A, Cunningham MW, Heeger PS. Anticardiac myosin immunity and chronic allograft vasculopathy in heart transplant recipients. J Immunol. 2011;187(2):1023-30.

75. Moliterno R, Woan M, Bentlejewski C, Qian J, Zeevi A, Pham S, et al. Heat shock protein-induced T-lymphocyte propagation from endomyocardial biopsies in heart transplantation. J Heart Lung Transplant. 1995;14(2):329-37.

76. Qian J, Moliterno R, Donovan-Peluso MA, Liu K, Suzow J, Valdivia L, et al. Expression of stress proteins and lymphocyte reactivity in heterotopic cardiac allografts undergoing cellular rejection. Transpl Immunol. 1995;3(2):114-23.

77. Moliterno R, Valdivia L, Pan F, Duquesnoy RJ. Heat shock protein reactivity of lymphocytes isolated from heterotopic rat cardiac allografts. Transplantation. 1995;59(4):598-604.

78. Latif N, Yacoub MH, Dunn MJ. Association of pretransplant antiheart antibodies against human heat shock protein 60 with clinical course following cardiac transplantation. Transplant Proc. 1997;29(1-2):1039-40.

79. Seemampillai B, Germack R, Felkin LE, McCormack A, Rose ML. Heat shock protein-27 delays acute rejection after cardiac transplantation: an experimental model. Transplantation. 2014;98(1):29-38. 